\title{
Evaluation of Age Related Changes in Cervical Spine in Saudi Arabian Adult Population: Using CT Scan Images
}

\author{
Ali Hassan A. Ali'1,2, Mohammad Aslam Siddiqui', Mohamed Abdelmohsen Bedewi', \\ Omar O. Serhan ${ }^{3}$ \\ ${ }^{1}$ Anatomy \& Radiology Departments, Salman Bin Abdulaziz University, Al-Kharj, KSA \\ ${ }^{2}$ Faculty of Medicine, Al Azhar University, Cairo, Egypt \\ ${ }^{3}$ King Khalid Hospital, Al-Kharj, KSA \\ Email: alihassan3750@yahoo.com, a.ali@sau.edu.sa
}

Received 14 January 2014; revised 20 February 2014; accepted 1 March 2014

Copyright $@ 2014$ by authors and Scientific Research Publishing Inc.

This work is licensed under the Creative Commons Attribution International License (CC BY). http://creativecommons.org/licenses/by/4.0/

(c) (i) Open Access

\begin{abstract}
Purpose: Cervical spine is considered to be the most moving part of vertebral column. It is located in a very important part of the body i.e. neck having some very important structures related to it. Any age related changes occurring in such a part of vertebral column may lead to many disorders and disabilities. Complete familiarity of this entire region anatomically as well as radiologically is therefore of utmost importance for the diagnosis and management of such disorders. Aim of this work is to evaluate the frequency of age related degeneration in cervical spine in Saudi adult asymptomatic subjects using CT scan images. Methods: In this study, 105 cases of symptomless adults ranging between 18 - 90 years of age were included. The cases were classified into 3 groups; adult group (18 - 35 years old), middle age group (36 - 55 years old) and old age group (56 - 90 years old). Their CT scans were performed in the department of radiology, King Khalid Hospital, Al Kharj and studied for any age related changes. Results: The first age group category included 35 cases; 20 had normal and 15 degenerative changes. The second category included 35 cases; 3 had normal and 32 degenerative changes. The third category included 35 cases. Single had normal and 34 degenerative changes. Conclusion: Asymptomatic degenerative changes are common in the cervical spine after 30 years of age in Saudi adult asymptomatic subjects.
\end{abstract}

\section{Keywords}

Cervical Spine, Age Changes, Spondylosis, CT 


\section{Introduction}

Cervical degenerative disease is common and it is often difficult to distinguish pathological changes from the normal aging process.

In the first two decades of life few changes occur within the spine, but from the third decade onwards degeneration is apparent. This tends to start at the level of the disc and is most common at C5/C6 and C6/C7. The majority of people over 50 years have radiological evidence of degenerative disease but only a small proportion will have neurological features [1].

Intervertebral disc degeneration is known to occur as a result of natural aging under the influence of various environmental factors [2]-[6]. Aging of the intervertebral discs with or without clinical symptoms occurs in everyone [7].

Ageing affects intervertebral discs throughout the entire spine, as shown by epidemiologic, cadaveric, and radiologic studies [8]-[16]. Age-related degenerative changes have been extensively studied in lumbar and cervical spine radiographs and magnetic resonance imaging (MRI) scans from asymptomatic subjects, and data from these studies are used as referable norms for diagnosing and treating patients with spinal disorders [17].

\subsection{Cervical Anatomy}

The upper surface of a typical cervical vertebral body is concave from side to side and convex in an anterior posterior direction. The upper projection of the lateral superior surface is known as the uncus and articulates with the vertebral body above at the unco-vertebral joint of Luschka. The pedicle is attached below the unco-vertebral joint on the body of the vertebra. Thus an intervertebral foramen is bounded in front by vertebral bodies, the uncovertebral joint, and the lateral disc. Posteriorly the foramen is bounded by the facet joint. Root compression may occur secondary to osteophyte formation arising from unco-vertebral joint medial to the root or from facet joint lateral to the root. These bony abnormalities are particularly well seen on computed 5 tomography (CT). A lateral disc prolapse may also compress the root.

The laminae enclose a relatively large spinal canal which is triangular in cross section and nicely defined on axial MRI. Cord compression may occur anteriorly, secondary to midline disc prolapse, osteophyte or more rarely ossified posterior longitudinal ligament. The cord may be compressed posteriorly by a hypertrophied ligamentum flavum [1].

The main joint between two cervical vertebrae is made up by a large spongy mass, the intervertebral disc. This disc sits between the two broad flat surfaces of the vertebral bodies. The disc is made up of specialized materials that act as a soft "glue" between the bones, while still allowing them to move. The disc is extremely important to spinal stability. However, it is a frequent site of degeneration or breakdown [1].

Normally, the neck is very flexible. It allows the head to rotate from side to side to nearly $180^{\circ}$, to flex forward to touch the chin to the chest and extend backwards to almost touch the back of the head to upper back. It also allows bending of head toward shoulder and all ranges in between these basic movements. These movements are afforded by various joints of the cervical spine [18].

\subsection{Cervical Spondylosis}

The term spondylosis refers to the bony overgrowths associated with aging of the spine.

Cervical spondylosis describes a non-specific degenerative process of the spine that may result in varying degrees of stenosis of the central spinal canal as well as the root canals. Factors contributing to this narrowing include degenerated disc, osteophyte, and hypertrophy of lamina, articular facets, ligamentum flavum, and posterior longitudinal ligament. Other relevant pathological processes include loss of the cervical lordosis and vertebral body subluxation. A congenitally narrow canal will precipitate the early development of symptoms [1].

Spondylosis is usually the end result of disc degeneration that has been present for a very long time. It may be associated with neck pain in some people.

Cervical spondylosis refers to common age-related changes in the area of the spine at the back of the neck. With age, the vertebrae (the component bones of the spine) gradually form bone spurs, and their shock-absorbing disks slowly shrink. These changes can alter the alignment and stability of the spine. They may go unnoticed, or they may produce problems related to pressure on the spine and associated nerves and blood vessels. This pressure can 
cause weakness, numbness, and pain in various areas of the body. In severe cases, walking and other activities may be compromised [19].

Plain cervical $x$ ray will often show evidence of degenerative changes with abnormalities being most prominent at C5/C6 and C6/C7 levels. Loss of disc height and formation of prominent osteophytes is a common finding in older patients and provides limited useful information for patient management [1].

Degenerative disorders of the cervical spine affect adult patients of any age, with a tendency for particular disorders to affect certain age groups. Cervical disk herniation is more characteristic in the young (less than 40 years old) while cervical spondylosis and stenosis are typically found in older patients. Degenerative disease of the spine refers to a breakdown of the normal architecture of various components of the cervical spine [18].

An important feature of disc degeneration is the reaction that the bone undergoes. It reacts by osteophyte formation. Osteophytes can be found near disc spaces and around facet joints and occupy space. If they grow in areas where nerves or the spinal cord are nearby they can impinge or compress these structures [18].

Computed tomography after the introduction of water soluble contrast agents is an accurate method for evaluating patients with neurologic symptoms [20]. It provides superior imaging of bone compared with MR imaging and better defines the anatomy of the neural foramina. Many surgeons therefore prefer CT myelography for the evaluation of radiculopathy. Computed tomography is often used to complement MR imaging to provide additional bony detail to characterize the lesion responsible for neural entrapment [21].

There have been few studies to study aging of the cervical spine in healthy subjects by using plain $\mathrm{x}$-ray, computed tomography or magnetic resonance imaging (MRI) [22].

Aim of this work was to evaluate the frequency of age related degeneration in cervical spine in Saudi adult asymptomatic subjects using CT scan images.

\section{Materials and Subjects}

One hundred and five symptomless Saudi persons between 18 - 90 years of age were included in this study. CT scan images of their cervical spine were obtained in the department of radio diagnostics, King Khalid Hospital Al-Kharj, KSA. It was ensured that they were free from any history of cervical spine or head disease, trauma or any systemic inflammatory disease.

The subjects were divided into three age categories. The first category included subjects between 18 to 35 years of age, the second between 36 to 55 years and the third between 56 to 96 years.

Before undertaking CT scans, a spinal surgeon conducted examination of the cervical spine including a neurological examination. Patients with neck pain, weakness or pain in the upper extremities, sensory disturbance or abnormal deep tendon reflexes of the upper extremities were excluded from the study.

Six cervical intervertebral levels from C2/3 to C7/T1 were evaluated for the study. Each level was assessed for occurrence of any degenerative changes such as loss of cervical spine curvature, disc space narrowing, osteophyte formation, osteopenia and sub-chondral multiple small cysts.

\section{Results}

Each age group was compared through two Statistical variables (normal CT findings which include normal alignment, normal lordotic cervical spine, normal disc spaces, and normal vertebral body heights) as shown in Figure 1 and (occurrence of degenerative changes which include loss of cervical spine curvature (Figures 2-5), disc space narrowing (Figure 2, Figure 4 and Figure 6), osteophytic changes (Figure 3 and Figure 4), osteopenia (Figure 3) and subchondral multiple small cysts (Figure 2 and Figure 4).

The first age group category included 35 cases (18 - 35 years). 20 had normal and 15 showed degenerative changes. The second category included 35 cases ( 36 - 55 years). 3 had normal and 32 showed degenerative changes. The third category included 35 cases (56 - 90 years). Single had normal and 34 showed degenerative changes (Figure 7).

\section{Discussion}

The asymptomatic degenerative CT scan findings of the cervical spine are probably normal age-related changes [23].

There is no generally accepted definition of degeneration morphologically, biochemically, or radiologically 


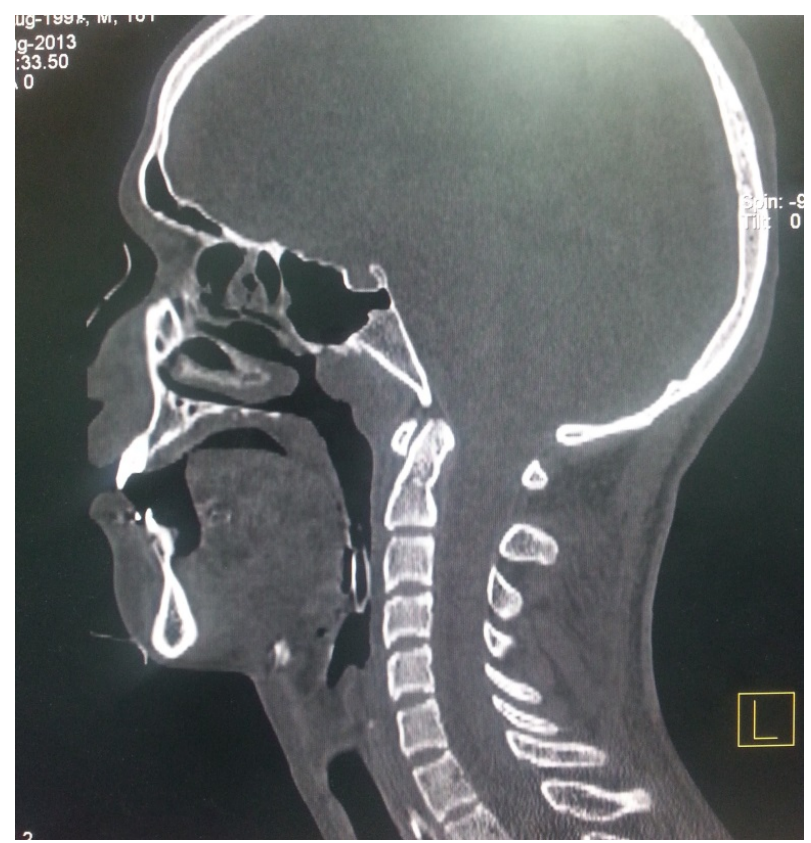

Figure 1. A sagittal Computed tomographic (CT) scanning cervical spine image of an 18 years male showing normal alignment of vertebrae, normal lordotic cervical spine curvature, No disc space narrowing and normal vertebral body heights.

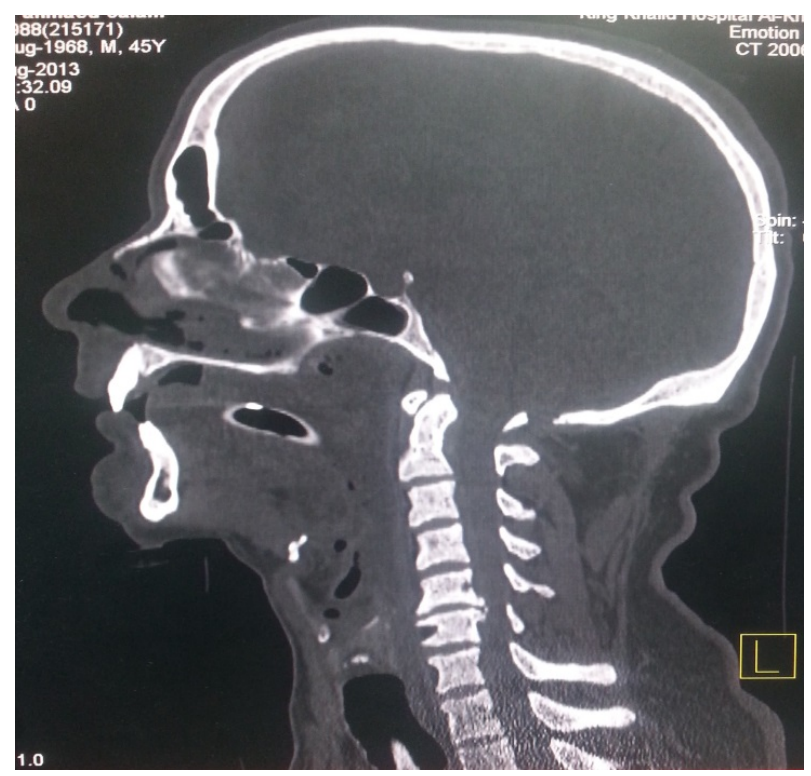

Figure 2. A sagittal Computed tomographic (CT) scanning cervical spine image of a 45 years male showing irregular outline, anterior and posterior wall end plates, peaking and sub chondral multiple small cysts, Sclerotic changes and narrowed multiple level disc spaces mainly at C4-5, loss of normal c-spine curvature and mild kyphotic changes at C3-6 level.

[24]. Various morphological manifestations of degeneration are taken into account in this study including disc space narrowing, loss of normal cervical curvature of spine, osteopenia, osteophytes and sub-chondral multiple cysts. 


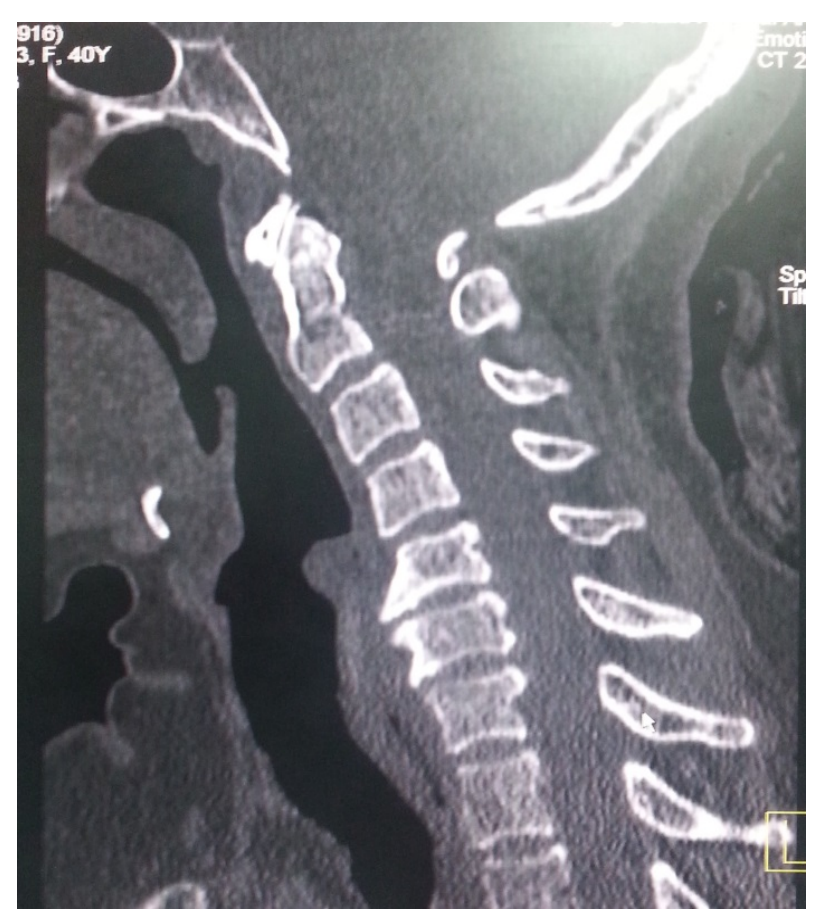

Figure 3. A sagittal Computed tomographic (CT) scanning cervical spine image of a 40 years female showing osteopenic changes, loss of c-spine lordosis, anterior vertebral body osteophytes with inferior peaking at the level of C4, 5 \& 6 .

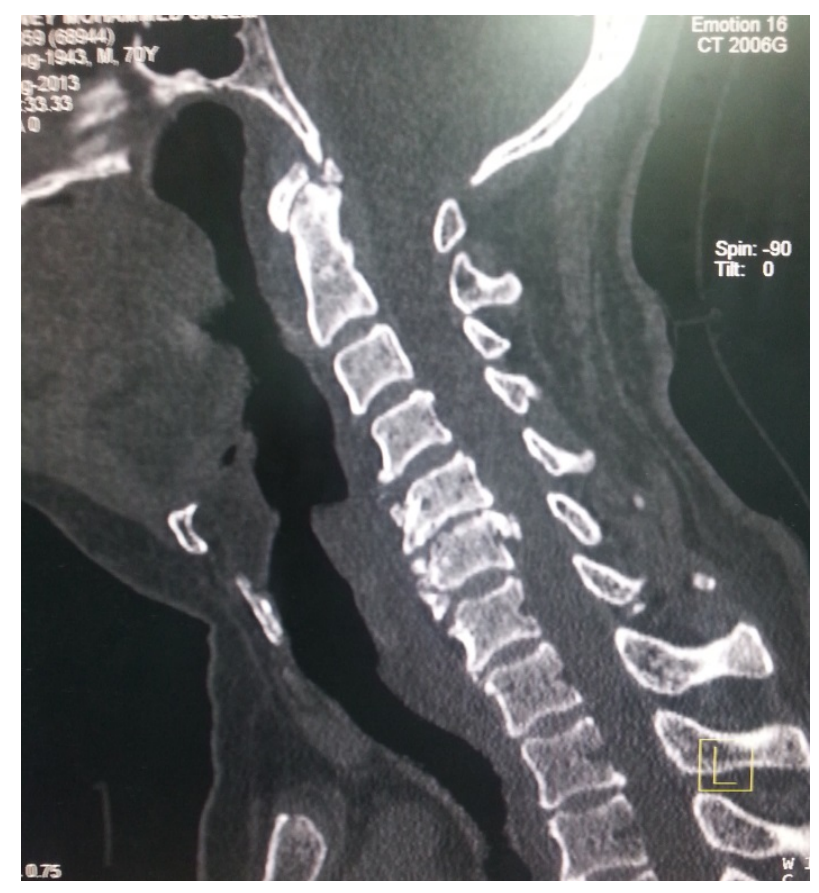

Figure 4. A sagittal Computed tomographic (CT) scanning cervical spine image of a 90 years male showing irregular outline, anterior and posterior wall end plates, peaking, sub-chondral multiple small cysts, sclerotic changes and narrowed multiple level disc spaces mainly at C5, 6. There is loss of normal cspine curvature. 


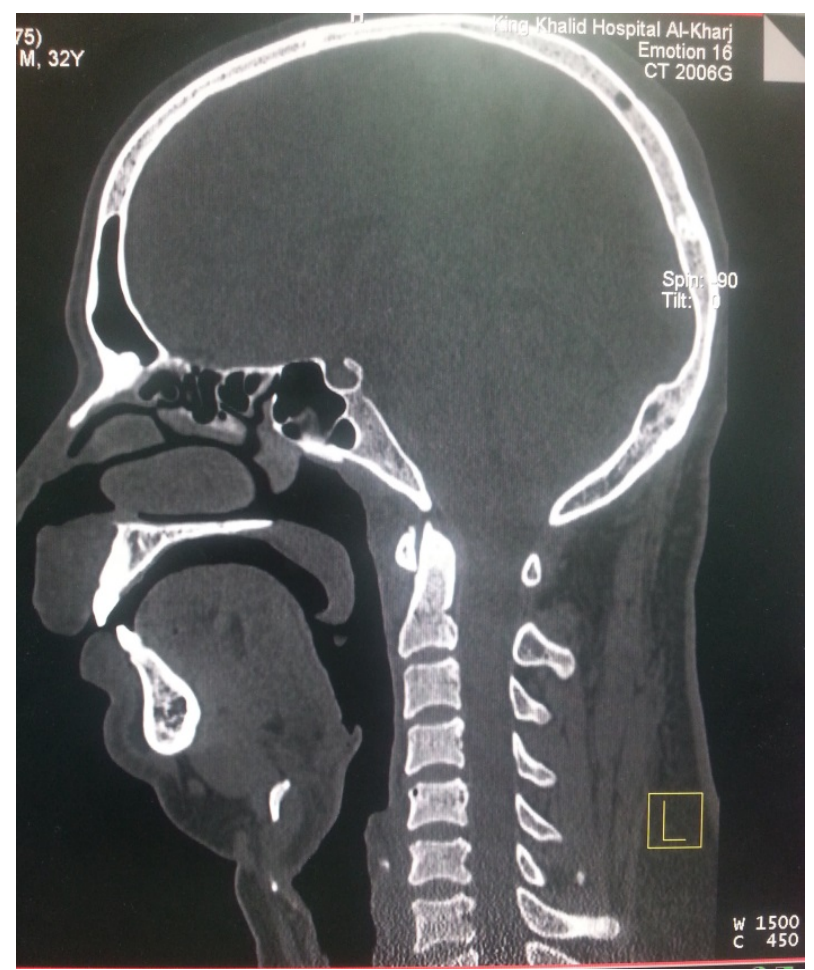

Figure 5. A sagittal Computed tomographic (CT) scanning cervical spine image of 32 years male showing irregular outline, anterior and posterior wall end plates, peaking, sclerotic changes and narrowed multiple level disc spaces as well as loss of normal c-spine curvature.

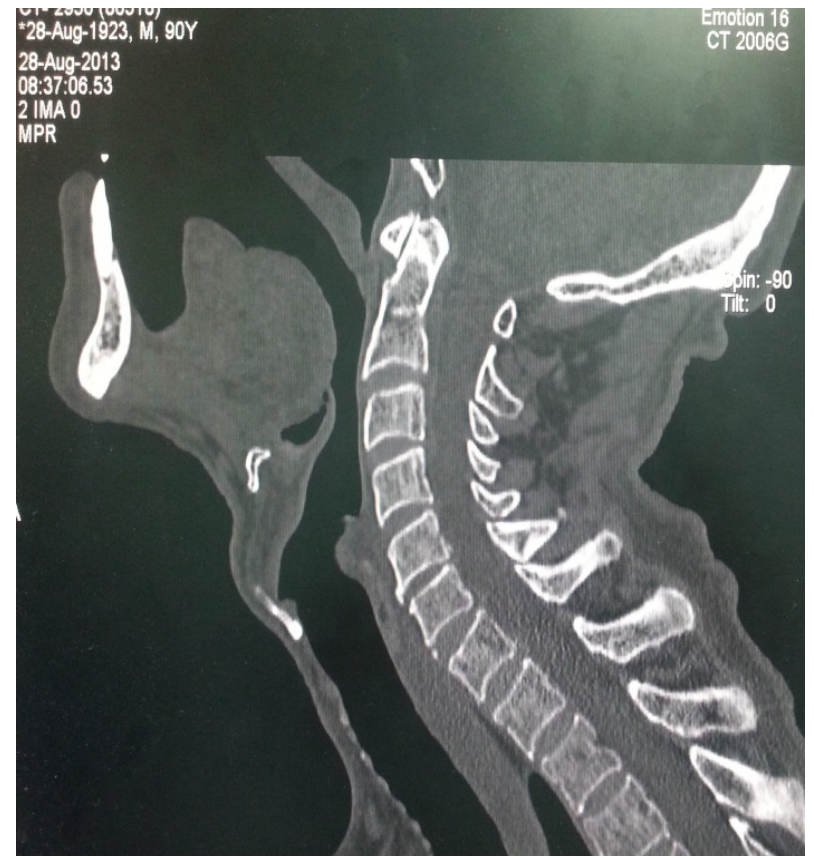

Figure 6. A sagittal Computed tomographic (CT) scanning cervical spine image of a 90 years male showing minimal degenerative changes of disc space narrowing, anterior osteophytes with inferior peaking at the level of C4, 5 \& 6 . 


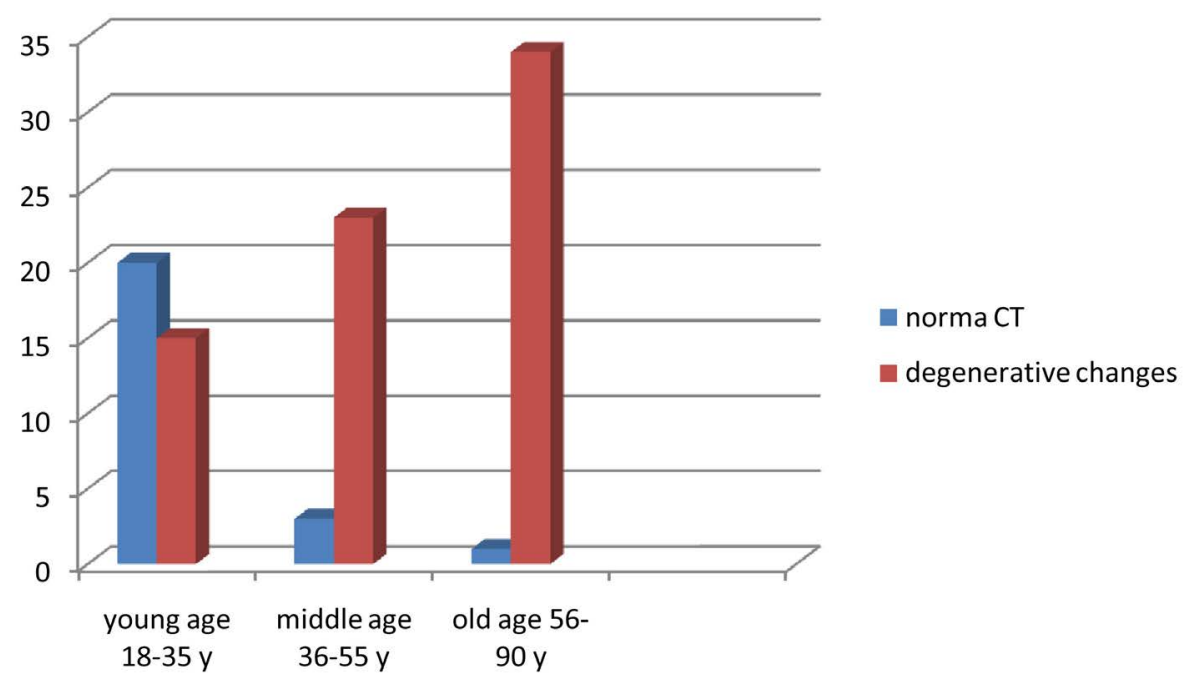

Figure 7. The occurrence of degenerative changes in cervical spine by age groups.

Previous cross sectional studies have demonstrated that age related changes in cervical spine are widely present even in asymptomatic healthy individuals. Reference [8] conducted MRI of cervical spine in such subjects and reported degenerative changes in 40 years of age and older subjects. Reference [8] conducted MRI of cervical spine in 89 healthy subjects using a $0.1 \mathrm{MRI}$ imager. Abnormal findings were recognized in $62 \%$ of the cases 40 years of age and older whereas the abnormal findings were rare in subjects younger than 40 years of age.

In another study of cervical spine MRI from 497 asymptomatic volunteers, Reference [17] also found that degenerative changes in cervical intervertebral discs were more frequent in older populations.

Reference [10] performed a 10 year long follow up study of healthy subjects without cervical spine related symptoms using plain x-ray. They recognized degenerative changes in $63 \%$ of individuals. This longitudinal study also revealed that the degenerative changes progressed in $81.1 \%$ of the initially asymptomatic subjects. $15 \%$ of the subjects however developed neck pain during follow up. According to them the progression of disc space narrowing and foraminal stenosis was more frequently observed in people 50 years and older while anterior compression of dura and spinal cord and posterior disc protrusion (PDP) were higher in people between 20 - 49 years of age. The differences in degree of progression in different age groups may reflect the presence of different stages in the degeneration process of intervertebral discs.

Tandem degenerative lumbar and cervical spine changes have been noted in clinical, anatomical, and genetic studies [25]-[30]. Reference [29] evaluated lumbar and cervical spine MRI images from 174 monozygotic and 154 dizygotic twins and reported intervertebral disc degeneration to be present in $74 \%$ individuals at lumber spine and $73 \%$ at cervical spine and concluded that genetic factors had a greater influence than environmental factors in these cases.

Reference [31] conducted a longitudinal study of twins in multiple countries, including Canada, Finland and USA, the Twin Spine Study, and reported that genetic factors were more closely associated with disc degeneration than the conventionally known environmental factors, such as smoking, vibration, and automobile driving.

Reference [28] found degenerative changes in both the lumbar and cervical spine in $80 \%$ of 234 cadaveric specimens studied, with more severe degeneration in the lumbar spine.

Our results suggest that early changes of the disc degeneration represented by anterior dural compression and posterior disc protrusion occur in younger age groups (20 - 50 years) where as more advanced structural changes in intervertebral disc such as disc space narrowing (as shown in Figure 2, Figure 4 and Figure 6) and foraminal stenosis occur in older age groups ( $>50$ years of age).

\section{Summary and Conclusion}

Age related changes in cervical spine are widely present in Saudi adult healthy population. The degenerative changes increased with increasing the age. 


\section{Acknowledgements}

This project was supported by the Deanship of Scientific Research at Salman bin Abdulaziz University, Al

Kharj, KSA. We are thankful to the deanship for this support.

\section{References}

[1] Malcolm, G.P. (2002) Surgical Disorders of the Cervicalspine: Presentation and Management of Common Disorders. Journal of Neurology, Neurosurgery \& Psychiatry, 73, i34-i41.

[2] Okada, E., Matsumoto, M., Fujiwara, H. and Toyama, Y. (2011) Disc Degeneration of Cervical Spine on MRI in Patients with Lumbar Disc Herniation: Comparison Study with Asymptomatic Volunteers. European Spine Journal, 20, 585-591. http://dx.doi.org/10.1007/s00586-010-1644-y

[3] Boden, S.D., McCowin, P.R., Davis, D.O., et al. (1990) Abnormal Magnetic-Resonance Scans of the Cervical Spine in Asymptomatic Subjects. A Prospective Investigation. The Journal of Bone and Joint Surgery. American Volume, 72, 1178-1184.

[4] Gore, D.R., Sepic, S.B. and Gardner, G.M. (1986) Roentgengraphic Findings of the Cervical Spine in Asymptomatic People. Spine, 11, 521-524. http://dx.doi.org/10.1097/00007632-198607000-00003

[5] Gore, D.R. (2001) Roentgengraphic Findings in the Cervical Spine in Asymptomatic Persons: A Ten-Year Follow-Up. Spine, 26, 2463-2466. http://dx.doi.org/10.1097/00007632-200111150-00013

[6] Lehto, I.J., Tertti, M.O., Komu, M.E., et al. (1994) Age-Related MRI Changes at 0.1 T in Cervical Discs in Asymptomatic Subjects. Neuroradiology, 36, 49-53. http://dx.doi.org/10.1007/BF00599196

[7] Matsumoto, M., Okada, E., Ichihara, D., Watanabe, K., Chiba, K., Toyama, Y., Fujiwara, H., Momoshima, S., Nishiwaki, Y., Hashimoto, T. and Takahata, T. (2010) Age-Related Changes of Thoracic and Cervical Intervertebral Discs in Asymptomatic Subjects. Spine, 35, 1359-1364.

[8] Boden, S.D., Davis, D.O., Dina, T.S., et al. (1990) Abnormal Magnetic Resonance Scans of the Lumbar Spine in Asymptomatic Subjects. A Prospective Investigation. The Journal of Bone and Joint Surgery, 72, 403-408.

[9] Jensen, M.C., Brant-Zawadzki, M.N., Obuchowski, N., et al. (1994) Magnetic Resonance Imaging of the Lumbar Spine in People without Back Pain. The New England Journal of Medicine, 331, 69-73. http://dx.doi.org/10.1056/NEJM199407143310201

[10] Gore, D.R., Sepic, S.B. and Gardner, G.M. (1986) Roentgenographic Findings of the Cervical Spine in Asymptomatic People. Spine, 11, 521-524. http://dx.doi.org/10.1097/00007632-198607000-00003

[11] Boden, S.D., McCowin, P.R., Davis, D.O., et al. (1990) Abnormal Magnetic-Resonance Scans of the Cervical Spine in Asymptomatic Subjects. A Prospective Investigation. The Journal of Bone and Joint Surgery. American Volume, 72, 1178-1184.

[12] Matsumoto, M., Fujimura, Y., Suzuki, N., et al. (1998) MRI of Cervical Intervertebral Discs in Asymptomatic Subjects. Journal of Bone and Joint Surgery. British Volume, 80, 19-24. http://dx.doi.org/10.1302/0301-620X.80B1.7929

[13] Lehto, I.J., Tertti, M.O., Komu, M.E., et al. (1994) Age-Related MRI Changes at 0.1 T in Cervical Discs in Asymptomatic Subjects. Neuroradiology, 36, 49-53. http://dx.doi.org/10.1007/BF00599196

[14] Yasuma, T., Koh, S., Okamura, T., et al. (1990) Histological Changes in Aging Lumbar Intervertebral Discs. Their Role in Protrusions and Prolapses. The Journal of Bone and Joint Surgery. American Volume, 72, 220-229.

[15] Leboeuf-Yde, C., Nielsen, J., Kyvik, K.O., et al. (2009) Pain in the Lumbar, Thoracic or Cervical Regions: Do Age and Gender Matter? Apopulation-Based Study of 34,902 Danish Twins 20 - 71 Years of Age. BMC Musculoskeletal Disorders, 20, 39. http://dx.doi.org/10.1186/1471-2474-10-39

[16] Mio, F., Hirose, Y., Chiba, K., et al. (2007) A Functional Polymorphism in COL11A1, which Encodes the a1 Chain of Type XI Collagen, Is Associated with Susceptibility to Lumbar Disc Herniation. The American Journal of Human Genetics, 81, 1271-1277. http://dx.doi.org/10.1086/522377

[17] Matsumoto, M., Okada, E., Toyama, Y., Fujiwara, H., Momoshima, S. and Takahata, T. (2013) Tandem Age-Related Lumbar and Cervical Intervertebral Disc Changes in Asymptomatic Subjects. European Spine Journal, 22, 708-713.

[18] Garfin, S.R. and Bono, C.M. (2013) Degenerative Cervical Spine Disorders Clear Explanations of Cervical Spine Conditions Causing Neck Pain. Spine Universe 2013.

[19] McCormack, B.M. and Weinstein, P.R. (1996) Cervical Spondylosis: An Update. Western Journal of Medicine, 165, 43-51.

[20] Bell, G.R. and Ross, J.S. (1992) Diagnosis of Nerve Root Compression-Myelography, Computed Tomography, and MRI. Orthopedic Clinics of North America, 23, 405-418.

[21] Brown, B.M, Schwartz, R.H., Frank, E. and Blank, N.K. (1988) Preoperative Evaluation of Cervical Radiculopathy 
and Myelopathy by Surface Coil MR Imaging. American Journal of Roentgenology, 151, 1205-1212. http://dx.doi.org/10.2214/ajr.151.6.1205

[22] Arthritis, Disc Problems and Neck Pain_Administrator @ 3:02 pm. Aging of the cervical spine. 14 April 2009.

[23] Matsumoto, M., Fujimura, Y., Suzuki, N., Nishi, Y., Nakamura, M., Yabe, Y. and Shiga, H. (1998) MRI of Cervical Intervertebral Discs Inasymptomatic Subjects. Journal of Bone \& Joint Surgery, 80-B, 19-24. http://dx.doi.org/10.1302/0301-620X.80B1.7929

[24] Yu, S., Haughton, V.M., Sether, L.A., Ho, K.C. and Wagner, M. (1989) Criteria for Classifying Normal and Degenerated Lumbar Intervertebral Disks. Radiology, 170, 523-526.

[25] Dagi, T.F., Tarkington, M.A. and Leech, J.J. (1987) Tandem Lumbar and Cervical Spinal Stenosis. Natural history, Prognostic Indices, and Results after Surgical Decompression. Journal of Neurosurgery, 66, 842-849. http://dx.doi.org/10.3171/jns.1987.66.6.0842

[26] Jacobs, B., Ghelman, B. and Marchisello, P. (1990) Coexistence of Cervical and Lumbar Disc Disease. Spine, 15, 1261-1264. http://dx.doi.org/10.1097/00007632-199012000-00006

[27] Aydogan, M., Ozturk, C., Mirzanli, C., et al.. (2007) Treatment Approach in Tandem (Concurrent) Cervical and Lumbar Spinal Stenosis. Acta Orthopaedica Belgica, 3, 234-237.

[28] Master, D.L., Eubanks, J.D. and Ahn, N.U. (2009) Prevalence of Concurrent Lumbar and Cervical Arthrosis: An Anatomic Study of Cadaveric Specimens. Spine, 34, E272-E275. http://dx.doi.org/10.1097/BRS.0b013e318195d10b

[29] Sambrook, P.N., MacGregor, A.J. and Spector, T.D. (1999) Genetic Influences on Cervical and Lumbar Disc Degeneration: A Magnetic Resonance Imaging Study in Twins. Arthritis \& Rheumatology, 42, 366-372. http://dx.doi.org/10.1002/1529-0131(199902)42:2<366::AID-ANR20>3.0.CO;2-6

[30] Matsumoto, M., Ichihara, D., Okada, E., et al.. (2010) Age-Related Changes in Thoracic Intervertebral Discs in Asymptomatic Subjects. Spine, 35, 1359-1364.

[31] Battié, M.C., Videman, T., Kaprio, J., et al.. (2009) The Twin Spine Study: Contributions to a Changing View of Disc Degeneration. The Spine Journal, 9, 47-59. http://dx.doi.org/10.1016/j.spinee.2008.11.011 